\title{
Development of Simple Bayesian Belief and Decision Networks as Interactive Visualization Tools for Determining Optimal In-row Spacing for 'Beauregard' Sweetpotato
}

\author{
Arthur Villordon ${ }^{1}$ \\ LSU AgCenter Sweet Potato Research Station, 130 Sweet Potato Road, \\ Chase, LA 71324
}
Ron Sheffield, Jose Rojas, and Yin-Lin Chiu
LSU AgCenter Department of Agricultural and Biological Engineering, Baton Rouge, LA 70803

Additional index words. Ipomoea batatas, storage root initiation, decision support, planting density

\begin{abstract}
A Bayesian belief network (BBN) model, which we named BxINROW/NET, was developed to represent the relationships among in-row spacing regimes, some agroclimatic variables known to influence storage root initiation, growing degree-days (GDDs) to harvest, and yield grades in 'Beauregard' sweetpotato grown in Louisiana. The model was developed from experimental data collected in a subset of years between 1990 and 2010 and assumed that soil moisture, weeds, and chemical injury were not limiting variables during the growing season. The BBN model error rates for storage root yields were $21 \%, 20 \%$, and $13 \%$ for U.S. \#1 (US1), canner, and jumbo grades, respectively, as estimated from repeated random partitioning of the modeling data set into training and testing partitions. In comparison, the error rates for a baseline logistic regression model were $56 \%, 54 \%$, and $\mathbf{5 3 \%}$ for US1, canner, and jumbo grades, respectively. The BBN model showed that GDDs to harvest (GDDH) as well as air and soil temperatures during the critical storage root initiation period [20 days after transplanting (DAT)] interacted with in-row spacing regimes to help determine the yield outcomes. Under a uniform irrigation management and minimum to intermediate GDDH (980 to 1495 GDDs), narrow (20 to $22 \mathrm{~cm})$ to intermediate in-row spacing regimes $(30 \mathrm{~cm})$ were associated with higher probabilities (56\% to $71 \%$ of cases) for attaining a high US1 yield (22 to $\left.45 \mathrm{t} \cdot \mathrm{ha}^{-1}\right)$. These outcomes were associated with minimum to intermediate soil and air heat units 20 DAT, representing early to intermediate planting dates. Under similar conditions, wide in-row spacing treatments $(38$ to $40 \mathrm{~cm})$ were associated with increased probabilities $(100 \%$ of cases) for achieving a high yield of jumbo or oversized roots if GDDH (1495 to 1710 GDDs) was maximized. BxINROW/NET was also used as the foundation model to construct Bayesian decision networks (BDNs) for fresh market and processing scenarios. The BDNs were constructed by adding a value or gain node associated with each yield grade. Nodes representing price per box and stand deficiency were also added. These nodes allowed the prediction of estimated net return associated with a specific in-row regime given some agroclimatic variables and GDDH. As a result of its reliance on conditions observed in the study, BxINROW/NET is only applicable to a local Louisiana growing area. Further study is necessary to determine the model's applicability in other regions and growing conditions.
\end{abstract}

In-row spacing helps to determine potential yield and financial return in sweetpotato production. For example, if rows are $1 \mathrm{~m}$ apart and cuttings are set $30 \mathrm{~cm}$ apart within rows $(\approx 33,333$ plants/ha $)$, and assuming that storage root yield will range from 0.5 to 1.4 $\mathrm{kg} / \mathrm{hill}$, then it is reasonable to expect that the potential yield will range from 14 to $42 \mathrm{t} \cdot \mathrm{ha}^{-1}$. Thus, producers might expect $\approx 25 \%$ to $50 \%$ increase in yield potential if planting density is increased by $50 \%$ to $\approx 50,000$ plants $/$ ha ( $20 \mathrm{~cm}$ in-row spacing, $1 \mathrm{~m}$ between rows) (K. Thornhill, personal communication). Current published evidence suggests that optimum sweetpotato in-row spacing distance depends on environment, cultivar, planting date (PD), and harvest date (HD) (Bouwkamp, 1985; Edmond and Ammerman, 1971; Schultheis et al., 1999; Steinbauer and Kushman, 1971; Sulaiman and Sasaki, 2001). Schultheis et al. (1999) investigated the effects of multiple inrow spacing regimes $(15,23,31$, and $38 \mathrm{~cm})$ and reported that the optimal in-row spacing varied with PD and expected HD for 'Beauregard' sweetpotato grown in North Carolina. In contrast, Guertal and Kemble (1997) observed that various in-row spacing treatments $(15,20,25$, and $30 \mathrm{~cm})$ did not influence US1 or fresh market 'Beauregard' in a 2-year study in Alabama. Such conflicting information can lead to uncertainty in management decisionmaking. The knowledge of the relationship among agroclimatic conditions and management variables that enables the producer to select the lowest possible planting density associated with optimum economic benefits will lead to production efficiency and reduce the risk of undesirable outcomes in sweetpotato production.

Recently, we have developed a BBN model that described the relationship between US1 yield and agroclimatic variables known to influence storage root initiation in 'Beauregard' sweetpotato (Villordon et al., 2010). BBNs and other crop growth modeling approaches are important components of agriculture-related decision support systems (Park et al., 2005). BBNs offer many advantages in modeling a domain (sweetpotato production system) that is characterized by interactive effects among agroclimatic, management, and biological variables. BBNs graphically and probabilistically describe the relationship between causal variables and the outcome of interest. An added benefit is that BBNs can learn from small and incomplete data sets that contain constant, discrete, and continuous variables (McCann et al., 2006; Uusitalo, 2007). When used as a decision support tool, a BDN ensures that treatment of risks and uncertainties is an intrinsic part of the decision-making process (Robertson and Wang, 2004). BDNs are constructed by converting the target input variable node into a decision node and adding a GAIN node (utility or value node expressed as net return per hectare) (Robertson and Wang, 2004). The graphical interface enables effective communication and enhances focus on key variables and relationships influencing a decision rather than being bogged down in the details (Robertson and Wang, 2004). This interface provides a highly visual means of representing the uncertainty surrounding potential outcomes of management interventions (Newton et al., 2007).

One of the main limitations of using BBNs is the need to discretize continuous variables, which could lead to lower precision (McCann et al., 2006). On the other hand, we gain the ability to use the efficient reasoning machinery of BBNs, especially if the relationships among variables are non-linear and complex (Myllymaki et al., 2002). Another limitation is that BBNs do not currently support feedback loops, which are sometimes beneficial in environmental modeling (Jensen, 2001).

BBNs have been used extensively in ecology and wildlife management to describe the influence of environmental variables on ecological-response variables (Marcot et al., 2006). In agriculture, BBNs have been used to model the effect of climate change in potato production (Solanum tuberosum) (Gu et al., 1994), predict yield response of winter wheat (Triticum aestivum) to fungicide application programs (Tari, 1996), develop a decision support system for growing malting barley (Hordeum vulgare) without the use of pesticides (Kristensen and Rasmussen, 2002), and quantify and demonstrate the impact of fertilizer best management practices (Nash and 
Hannah, 2011). The primary objective of our work was to use the BBN modeling approach to discover causal dependencies among some agroclimatic variables, GDDs, in-row spacing regimes, and storage root yield grades in 'Beauregard' sweetpotato grown in Louisiana. A secondary objective was to develop BDNs for optimizing in-row spacing decisions for fresh market and processing scenarios of sweetpotato production.

\section{Materials and Methods}

Study site. Field experiments were conducted in 2002, 2007, 2008, and 2010 in welldrained research fields in Chase, LA (lat. $32^{\circ} 6^{\prime} \mathrm{N}$, long. $91^{\circ} 42^{\prime} \mathrm{W}$ ). Data from previous trials conducted in 1990, 1991, and 1992 (Mulkey and McLemore, 1992; Mulkey et al., 1994) were added to the data set. The soil taxonomic class was fine-silty, mixed, active, thermic Typic Glossaqualfs. For studies conducted from 1990 to 1992 , 'Beauregard' cuttings were obtained from foundation seed roots $(5.1$ to $8.9 \mathrm{~cm}$ in diameter and 7.6 to $22.9 \mathrm{~cm}$ in length) in plant beds. For this study period, foundation seed roots were maintained using visual selection of off-type plants, mutations, internal cork, and other disorders as described by Mulkey and Hernandez (1994). Starting in 2002, cuttings were obtained from virus-tested 'Beauregard' G1 "seed roots" in plant beds. Field preparation activities, including fertilizer rates, herbicide, and insecticide applications, were very similar in each year (Mulkey and McLemore, 1992; Mulkey et al., 1994; Villordon et al., 2010). In 1990 and 1991, plot size was four rows $\times 6 \mathrm{~m}$ on 1-m centers. In 1992, plot size was six rows $\times 6 \mathrm{~m}$ on $1-\mathrm{m}$ centers. Plot size in 2002 , 2007 , and 2008 was four rows $\times 6 \mathrm{~m}$ on $1.1-\mathrm{m}$ centers. Data were collected from the middle two rows for field trials conducted between 1990 and 2008. Plot size for 2010 was five rows $\times 3 \mathrm{~m}$ on $1.1-\mathrm{m}$ centers and data were collected from the middle row. Starting in 2007, 'O'Henry,' a white-skinned, whitefleshed cultivar (Clark and Hoy, 2006), was

Received for publication 22 Mar. 2011. Accepted for publication 4 Oct. 2011.

Portions of this research were supported by the Louisiana Sweetpotato Advertising and Development Fund, Louisiana Sweet Potato Growers Association, NSF/EPSCoR under Award No. EPS-0701491, and USDA-NIFA-SCRI Award No. 2009-51181-06071. We thank Tim Talbot, Bill McLemore, and Jason W. Franklin for their assistance in the conduct of some or all field studies referenced in this work. We thank anonymous reviewers for valuable feedback and constructive comments.

Approved for publication by the Director of the Louisiana Agricultural Experiment Station as manuscript number 2011-260-5646.

Mention of trademark, proprietary product or method, and vendor does not imply endorsement by the Louisiana State University AgCenter nor its approval to the exclusion of other suitable products or vendors.

${ }^{1}$ To whom reprint requests should be addressed; e-mail avillordon@agcenter.lsu.edu. used as a guard plant on each end of the plot to reduce the occurrence of oversized roots associated with the lack of intrahill competition in these locations. 'O'Henry' is a mutant selection of 'Beauregard' and did not represent any competitive difference. Uniform cuttings (eight to 10 fully opened leaves) were obtained from plant beds and set within 2 to $3 \mathrm{~d}$.

Within 2 to $3 \mathrm{~d}$ after transplanting, supplemental overhead irrigation was supplied with a traveling irrigation sprinkler if a rainfall event did not occur. This irrigation method helped to reduce desiccation among transplants and promoted establishment (initiation of adventitious roots) within 3 to $7 \mathrm{~d}$. Stand counts were conducted between 15 and 35 DAT. Plant stands ranged from $90 \%$ to $100 \%$ in all years. Irrigation scheduling for studies conducted between 1990 and 2002 was based on a checkbook method (Lundstrom and Stegman, 1988). The amount of rainfall or supplemental irrigation applied in each growing season was generally equivalent to $25 \mathrm{~mm}$ per week for 15 to 16 weeks. Starting in 2007, supplemental irrigation was based on soil moisture sensor data and irrigation was applied when soil moisture at the $15-\mathrm{cm}$ depth approached $25 \%$ of field capacity. For the soil type used in the study, $16 \%$ volumetric water content (VWC) represented $\approx 50 \%$ of field capacity. Soil moisture was monitored with a HydroSense Soil Water Content Management System (CS-620, 20-cm probe; Campbell Scientific, Inc., Logan, UT). This soil moisture range has previously been calibrated (Constantin et al., 1974) and validated (Villordon et al., 2010) as optimum for sweetpotatoes grown on the soil type prevalent in the area. In 2010, soil moisture monitoring was augmented by the installation of soil moisture sensors (ECH2O EC-5; Decagon Devices Inc., Pullman, WA) linked to data loggers (EM50; Decagon Devices Inc.). The data loggers were connected wirelessly to a data collection device (DataStation; Decagon Devices Inc.). Soil moisture sensors (5 $\mathrm{cm}$ in length) were installed vertically at two depths $(5$ and $15 \mathrm{~cm})$ in two plots in each PD. All supplemental irrigation was delivered by a traveling irrigation sprinkler or furrow irrigation (after 35 DAT).

At harvest, storage roots were graded according to USDA standards (U.S. Department of Agriculture, 2005): US1 (5.1 to $8.9 \mathrm{~cm}$ in diameter and 7.6 to $22.9 \mathrm{~cm}$ in length), canner (CAN; 2.5 to $5.1 \mathrm{~cm}$ in diameter and 5.1 to $17.8 \mathrm{~cm}$ in length), and jumbo (JUM; larger than both groups). Total marketable yield was defined as the sum of US1, CAN, and JUM. The PDs and HDs as well as yield data within each year are shown in Table 1. In 2010, storage root counts at harvest were performed in two replicates in each of three PDs (12 May, 20 May, and 27 May). The storage root count data were natural log transformed and means comparison was carried out following the GLM procedure of SAS (Version 9.2; SAS Institute, Cary, NC).

Agroclimatic data were obtained from an on-site National Oceanic and Atmospheric Administration weather station (air and soil temperatures). Air and soil temperatures within this period have previously been found to be significant predictor variables of storage root yield in 'Beauregard' grown in Louisiana assuming soil moisture was not a limiting variable (Villordon et al., 2009a, 2010). Togari (1950) previously reported that environmental conditions 20 DAT directly influenced storage root initiation, which in turn determined yield potential. GDDHs were calculated for all PD and HD combinations to adjust for differences in growing periods (Riha et al., 1996). We have previously empirically derived a method for calculating GDD for Louisiana-grown sweetpotatoes (Villordon et al., 2009a). Air and soil temperatures 20 DAT was represented as air (GDD20) and soil (SHU20) heat units, respectively (Villordon et al., 2010). Representations of air and soil temperatures as air and soil heat units, respectively, have been used routinely in crop modeling (Pale et al., 2003; Riha et al., 1996). The air and soil temperature ranges as well as estimates of heat unit accumulations are presented in Table 2. The modeling data set consisted of the following column headers (names of variables): US1, CAN, JUM, TMY, GDD20, GDDH, SHU20, and in-row spacing regime (INROW). In the modeling scheme, INROW was a discrete variable and the various spacing treatments were also referred to as "narrow" (20 to $22 \mathrm{~cm})$, "intermediate" $(30 \mathrm{~cm})$, and "wide" (38 to $40 \mathrm{~cm})$.

Data pre-processing and model development. There were 51 records in the modeling data set. The data were compiled in an Excel spreadsheet (Version 7; Microsoft, Redmond, WA) and transformed by natural logarithms. Transformation of quantitative variables was performed to make the estimation process more robust and reduce unstable results (Kuhnert and Hayes, 2009). Correlation analysis was performed among variables to determine if linkages were going to be established during model development (Cain, 2001; Marcot et al., 2006). We adopted the general guidelines that Marcot et al. (2006) proposed for developing, testing, and revising BBNs. The first step comprised creating influence diagrams of hypothesized "causal web" variables. The first influence diagram (Model 1) was developed based on a correlation analysis among the variables (Fig. 1). A second diagram (Model 2) was developed using the "learning wizard" function of Hugin Researcher (Version 7.2; Hugin Expert A/S, Aalborg, Denmark) (Fig. 1). In this mode, Hugin Researcher attempted to learn the model structure without prior assumptions of any relationships among the variables in the data set. The only intervention was to ensure that US1, CAN, and JUM were linked to TMY, i.e., US1, CAN, and JUM determined TMY.

Parameter learning. Parameter learning (determination of conditional probability table at each node) was performed using Netica software (Version 4.09; Norsys Software Corp., Vancouver, Canada). The procedures for parameter learning from experimental data stored in a spreadsheet were based on the procedures described in Netica's built-in 
Table 1. Storage root yields of 'Beauregard' sweetpotato grown under various in-row spacing regimes in Louisiana.

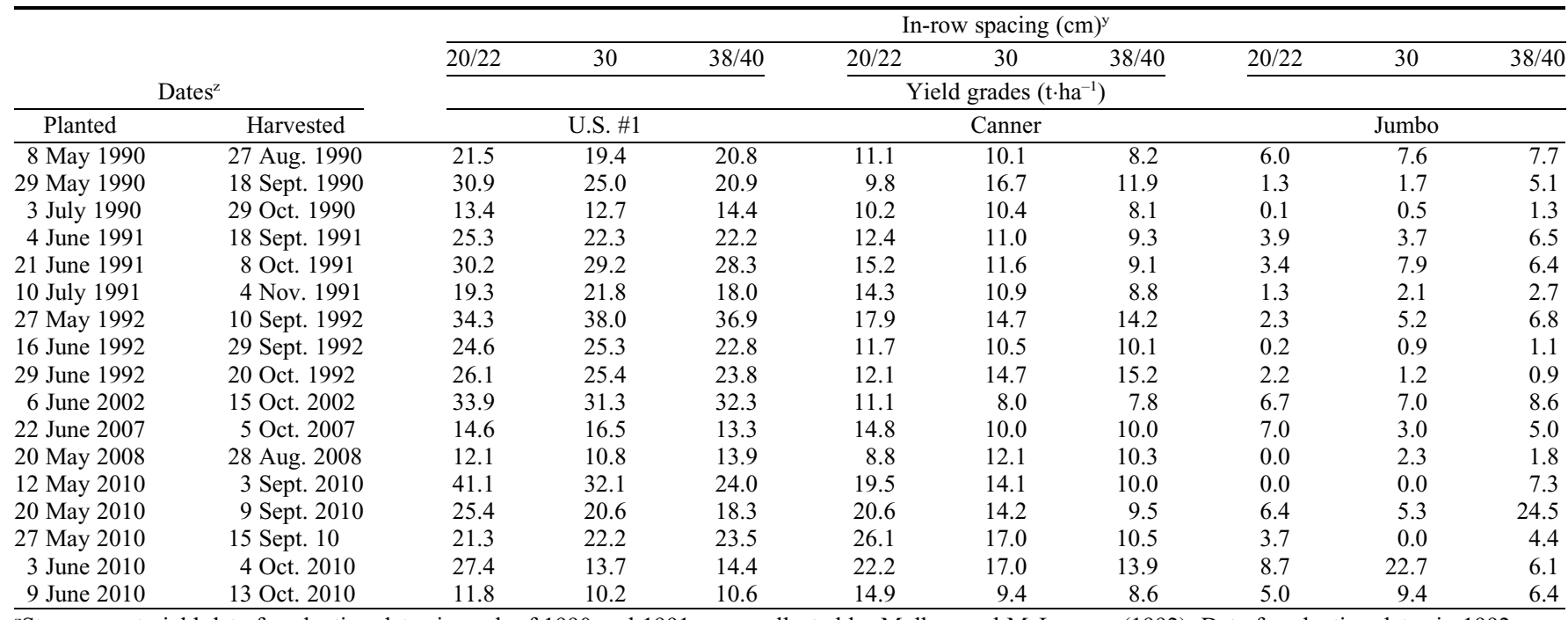

${ }^{\mathrm{z}}$ Storage root yield data for planting dates in each of 1990 and 1991 were collected by Mulkey and McLemore (1992). Data for planting dates in 1992 were collected by Mulkey et al. (1994). All other data were collected by A. Villordon. In-row spacing for 1990 to $1992=22$, 30 , and $38 \mathrm{~cm}$; in-row spacing for trials between 2002 and 2010: 20, 30, and $40 \mathrm{~cm}$. Growing conditions are described in "Materials and Methods."

${ }^{y}$ U.S. $\# 1=5.1$ to $8.9 \mathrm{~cm}$ diameter and 7.6 to $22.9 \mathrm{~cm}$ in length; canner $=2.5$ to $5.1 \mathrm{~cm}$ in diameter and 5.1 to $17.8 \mathrm{~cm}$ in length; and jumbo $=$ larger than both groups (U.S. Department of Agriculture, 2005).

Table 2. Some agroclimatic data and accumulated air and soil heat units for 'Beauregard' sweetpotato grown in Louisiana.

\begin{tabular}{|c|c|c|c|c|c|c|c|c|c|}
\hline \multirow[b]{4}{*}{$\mathrm{Yr}$} & & & \multicolumn{4}{|c|}{ Agroclimatic data $\left({ }^{\circ} \mathrm{C}\right)^{\mathrm{y}}$} & \multirow{2}{*}{\multicolumn{3}{|c|}{ Heat unit accumulations ${ }^{\mathrm{x}}$}} \\
\hline & & & \multicolumn{4}{|c|}{$20 \mathrm{DAT}$} & & & \\
\hline & \multicolumn{2}{|c|}{ Dates $^{z}$} & & & & & \multicolumn{2}{|c|}{$20 \mathrm{DAT}$} & \multirow[b]{2}{*}{ GDDH } \\
\hline & PD & HD & Maximum & Minimum & Maximum & $\overline{\text { Minimum }}$ & Air & Soil & \\
\hline \multirow[t]{3}{*}{1990} & 8 May & 27 Aug. & 28.4 & 17.4 & 27.7 & 20.4 & 194.0 & 108.0 & 1425.0 \\
\hline & 29 May & 18 Sept. & 32.4 & 21.3 & 32.1 & 24 & 301.0 & 195.0 & 1468.0 \\
\hline & 3 July & 29 Oct. & 33.2 & 21.6 & 32.3 & 26 & 314.0 & 218.0 & 1148.0 \\
\hline \multirow[t]{3}{*}{1991} & 4 June & 18 Sept. & 32.2 & 22 & 30.4 & 24.8 & 320.0 & 186.0 & 1422.0 \\
\hline & 21 June & 8 Oct. & 33.3 & 22.7 & 31.2 & 25.9 & 332.0 & 205.0 & 1251.0 \\
\hline & 10 July & 4 Nov. & 34 & 22.4 & 32.7 & 26.9 & 331.0 & 230.0 & 1068.0 \\
\hline \multirow[t]{3}{*}{1992} & 27 May & 10 Sept. & 28.9 & 18.3 & 25.5 & 21.1 & 240.0 & 98.0 & 1304.0 \\
\hline & 16 June & 29 Sept. & 32.4 & 21 & 29.3 & 23.9 & 305.0 & 166.0 & 1198.0 \\
\hline & 29 June & 20 Oct. & 33.6 & 22.3 & 31.1 & 25.4 & 329.0 & 198.0 & 981.0 \\
\hline 2002 & 6 June & $15 \mathrm{Oct}$ & 32.3 & 20 & 31.9 & 25.1 & 316.0 & 204.0 & 1704.0 \\
\hline 2007 & 22 June & 5 Oct. & 32.1 & 21.7 & 29.5 & 25 & 320.0 & 180.0 & 1400.0 \\
\hline 2008 & 20 May & 28 Aug. & 32.6 & 21.9 & 28.1 & 23.7 & 326.0 & 152.0 & 1317.0 \\
\hline \multirow[t]{5}{*}{2010} & 12 May & 3 Sept. & 32.3 & 19 & 31.7 & 23.2 & 322.0 & 184.0 & 1549.0 \\
\hline & 20 May & 9 Sept. & 32.9 & 21.5 & 35.3 & 23.5 & 326.0 & 222.0 & 1505.0 \\
\hline & 27 May & 15 Sept. & 33.6 & 22.5 & 38.1 & 24.2 & 326.0 & 257.0 & 1488.0 \\
\hline & 3 June & 4 Oct. & 35 & 23.7 & 41.2 & 25.8 & 329.0 & 305.0 & 1581.0 \\
\hline & 9 June & 13 Oct. & 36 & 23.9 & 42.8 & 26.1 & 334.0 & 322.0 & 1529.0 \\
\hline Mean & & & 32.7 & 21.4 & 32.4 & 24.4 & 309.7 & 201.8 & 1372.8 \\
\hline $\mathrm{SD}$ & & & 1.8 & 1.7 & 4.6 & 1.7 & 36.9 & 58.1 & 194.4 \\
\hline
\end{tabular}

${ }^{\mathrm{z} P D}=$ planting date; $\mathrm{HD}=$ harvest date.

${ }^{y}$ Agroclimatic data were obtained from the NOAA National Data Centers Virtual Data System database for station ID\# 169806 (Winnsboro 5 SSE; lat. $32^{\circ} 06^{\prime}$ N/ long. $91^{\circ} 42^{\prime} \mathrm{W}$ ) located in Chase, LA. DAT = days after transplanting. Values represent means. Soil temperature was measured at $10 \mathrm{~cm}$.

${ }^{\mathrm{x}} \mathrm{GDDH}=$ growing degree-days to harvest. Calculations for soil and heats are described in "Materials and Methods."

user manual. The learning algorithm was the expectation-maximization method. Automatic discretization was performed using Netica's built-in discretization algorithm. Agroclimatic variables were discretized into three states, whereas yield-related variables were discretized into two states. Previous modeling experiments showed that three-state discretization of yield variables resulted in poor models with high error rates (Villordon et al., 2010).

Model assessment and selection. The performance of the candidate BBN models was estimated by randomly partitioning the modeling data set into 10 unique pairs (pseudo replications) of training and testing data sets $(\mathrm{n}=50 \%)$ using SAS Enterprise Miner (Version 9.2; SAS Institute). Within each pseudoreplicate, the model was parameterized using the training partition and subsequently tested on the testing partition to generate the error estimates for US1, CAN, and JUM yield grades. Measurements of accuracy included error rate and area under the curve (AUC) analysis (mean of 10 pseudoreplicates). Error rate was calculated by identifying the number of cases that did not match the predictions (Hugin Researcher Version 7.2 manual). In AUC analysis, if
$\mathrm{AUC}=0.50$, then the model is randomly guessing the outcome; an accurate classifier should have an AUC of more than 0.50 (Fawcett, 2006). These values were calculated using Hugin Researcher's analysis wizard. The predictive accuracy of the candidate BBN models was compared with logistic regression (baseline model). Logistic regression has been used to provide context for comparing the performance of $\mathrm{BBN}$ models developed for predicting outcomes (Reiz and Csato, 2009; Watt and Bui, 2008). The modeling data set was subjected to logistic regression analysis using the full model in 


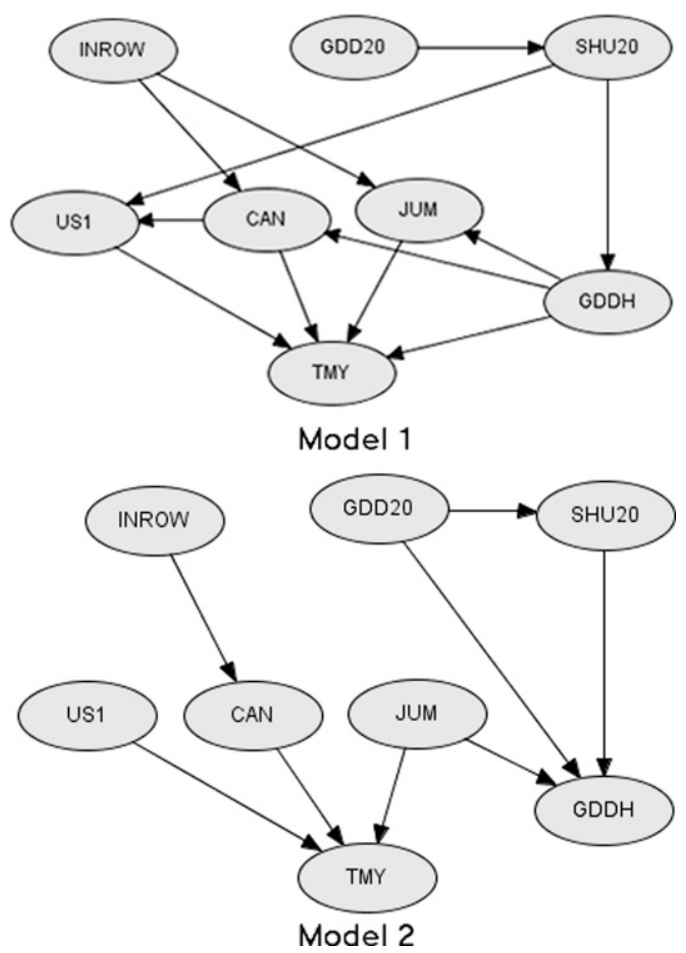

Fig. 1. Candidate Bayesian belief network structures, designated as Models 1 and 2 for representing the relationship among in-row spacing regimes, some agroclimatic variables, growing degree-days, and yield grades for 'Beauregard' sweetpotato grown in Louisiana. INROW = in-row spacing; SHU20 = accumulated soil heat units $20 \mathrm{~d}$ after transplanting (DAT); GDD20 = accumulated air heat units 20 DAT; US1 = U.S \#1 yield grade; $\mathrm{CAN}=$ canner yield grade; $\mathrm{JUM}=$ jumbo yield grade; $\mathrm{TMY}=$ total marketable yield (US1 + CAN + JUM); GDDH = growing degree-days or accumulated heat units between 20 DAT and harvest. Units of yield $=\mathrm{t} \cdot \mathrm{ha}^{-1}$.

SAS Analyst (Version 9.2; SAS Institute). AUC values from the logistic regression analyses were calculated using the receiver operating characteristic curve procedure in SPSS (Version 15.0; SPSS Inc., Chicago, IL). AUC values and error rates among the models were subjected to analysis of variance using Proc GLM in SAS (SAS 9.2; SAS Institute).

Development of decision networks. Based on the model assessment results from the previous section, Model 1 was used as a foundation model for the development of BDNs for fresh market and processing production scenarios. The BDNs were constructed by converting the INROW node into a decision node and adding a GAIN node (utility or value node expressed as net return per hectare) (Robertson and Wang, 2004). The BDN construction was performed using Netica software and consisted of highlighting the INROW node followed by the selection of the "Decision" option from the menu $(\rightarrow$ Modify $\rightarrow$ Kind $\rightarrow$ Decision). After converting the BBN into a BDN, the target node (INROW) showed calculated net return opposite each variable state, i.e., in-row spacing distance, instead of probabilities of states of the variable. To further simulate actual field and operating conditions, STAND and PACKOUT (for fresh market BDN only) discrete nodes were added. The STAND discrete node was used to represent yield loss resulting from stand deficiency (survival rate). The PACKOUT discrete node was used to represent losses associated with shrinkage in storage that impacts packing operations of US1 roots. A PPB X (price per 18-kg box where $\mathrm{X}=$ yield grade) discrete node was added to simulate returns under various scenarios of prices paid to the producer. Simulated prices paid for fresh market and processing/canners were based on values reported by Hinson and Boudreaux (2009). A COST REDUCTION discrete node was added to the processing $\mathrm{BDN}$ to simulate added value if production efficiencies are gained through reduction of operating expenses, mechanization, and other bulk handling technologies. We adopted the partial budgeting approach used by Schultheis et al. (1999) in estimating return on investment associated with adopting an inrow spacing regime. The calculated net returns of the GAIN conditional utility table were based on estimated costs of producing sweetpotatoes in Louisiana using six-row equipment (Hinson and Boudreaux, 2009). Netica automatically generated the conditional utility table and populated all columns (except the GAIN column) after the relevant parent nodes were linked to the GAIN node. For example, the processing conditional utility table had 1152 rows representing all possible combinations of INROW, STAND, US1, CAN, JUM, PPB, COST REDUCTION, and GAIN. The GAIN associated with each specific combination of variable ranges was calculated in a spreadsheet and the values were subsequently pasted into the GAIN column. For calculation of the estimated net returns, only the following operations/operating inputs were adjusted with each in-row spacing regime: cost of planting materials, labor costs for cutting of planting materials, equipment operating costs, and planting labor. Net revenue was calculated using this formula: (PPB $\times$ number of boxes per hectare) - total direct expenses/hectare. The adjusted costs for narrow (20 to $22 \mathrm{~cm}$ ) and wide (38 to $40 \mathrm{~cm}$ ) in-row spacing regimens were estimated to be $1.5 \times$ and $0.75 \times$, respectively, relative to the intermediate $(30$ $\mathrm{cm}$ ) in-row spacing. All other costs such as operations related to harvesting, plastic crates, and storage bins were assumed to be constant.

\section{Results and Discussion}

There was a wide range of agroclimatic variability 20 DAT within and across years (Table 2). Air and soil heat unit accumulations 20 DAT reflected the variability in prevailing air and soil temperatures during the critical storage root initiation phase. PDs ranged from as early as 8 May 1990 (GDD 20 $\mathrm{DAT}=194)$ to as late as 10 July 1991 (GDD 20 DAT $=331)$. SHU20 ranged from 98 $(\mathrm{PD}=27$ May 1992) to $322(\mathrm{PD}=9$ June 2010). GDDH values, representing variability in growing periods, ranged from $981(\mathrm{PD}=29$ June $1992, \mathrm{DH}=20$ Oct. 1992) to $1549(\mathrm{PD}=$ 12 May 2010, DH = 3 Sept. 2010). We have previously reported that when sampled within 20 DAT, adventitious roots that showed anatomical evidence of initiation were found to comprise $86 \%$ of storage roots sampled at 60 DAT in 'Beauregard' sweetpotato grown under well-watered conditions (Villordon et al., 2009b). Current available evidence suggests that air and soil temperatures directly influence storage root formation or growth. For example, Ravi and Indira (1999) noted that night air temperature below $15^{\circ} \mathrm{C}$ suppressed storage root formation, whereas air temperatures greater than $30{ }^{\circ} \mathrm{C}$ increased indole acetic acid oxidase activity, which caused reduction in storage root formation and growth. Kays (1985) has previously documented that $29{ }^{\circ} \mathrm{C} / 21{ }^{\circ} \mathrm{C}$ day/night air temperatures favored storage root development and that soil temperatures above $30{ }^{\circ} \mathrm{C}$ substantially decreased storage root yield. In 'Beauregard', we have documented that adventitious roots and storage roots were initiated at the lower nodes or the "cut end" of the transplant when soil temperatures approached or exceeded $30{ }^{\circ} \mathrm{C}$ in the upper $10 \mathrm{~cm}$ of the soil profile during the establishment and storage root initiation phases resulting in the reduction of adventitious root counts and storage root yields (Villordon et al., 2010, 2011).

Model 1 consistently performed better than the baseline logistic regression model for all measures of model accuracy (Table 3 ). Model 1 had a lower error rate $(21.0 \%)$ for US1 compared with the baseline logistic regression model (56.4\%). Model 1 also had a relatively higher AUC (0.83) for US1 compared with Model $2(0.75)$ and the baseline model (0.50). Logistic regression AUC values for CAN and JUM were all significantly lower compared with Model 1 and Model 2. Model 1 was subsequently selected 
Table 3. Predictive performance of Bayesian belief network and logistic models that represent the relationship of some agroclimatic variables, growing degreedays, in-row spacing regimes, and yield grades for 'Beauregard' sweetpotato grown in Louisiana.

\begin{tabular}{|c|c|c|c|c|c|c|c|c|c|c|c|c|}
\hline \multirow{3}{*}{$\begin{array}{l}\text { Model } \\
\text { Model } 1\end{array}$} & \multicolumn{12}{|c|}{ Yield grade } \\
\hline & \multicolumn{4}{|c|}{ US \#1 } & \multicolumn{4}{|c|}{ Canner } & \multicolumn{4}{|c|}{ Jumbo } \\
\hline & 0.85 & $(0.01) \mathrm{a}$ & 21.00 & $(1.98) \mathrm{b}$ & 0.83 & $(0.01) \mathrm{a}$ & 20.66 & $(1.14) \mathrm{b}$ & 0.89 & $(0.01) \mathrm{a}$ & 13.03 & $(1.65) \mathrm{c}$ \\
\hline Logistic & 0.50 & $(0.01) \mathrm{c}$ & 56.40 & $(2.56) \mathrm{a}$ & 0.50 & $(0.01) \mathrm{b}$ & 54.40 & $(1.83) \mathrm{a}$ & 0.53 & $(0.02) \mathrm{c}$ & 53.30 & $(3.25) \mathrm{a}$ \\
\hline
\end{tabular}

zModel structures are described in "Materials and Methods."

${ }^{\mathrm{y}} \mathrm{AUC}=$ area under the curve. Calculation of AUC is described in "Materials and Methods."

${ }^{x}$ Error rates were estimated through repeated partitioning of the modeling data set into training and testing partitions, in which each pair of randomly generated training and testing partition represented a pseudoreplicate. Mean separation within columns by least significant difference at $P<0.01$. Values in parentheses represent SE estimates. Calculation of error rates is described in "Materials and Methods."

as the prototype working model. This model's structure (arcs or links between nodes) was determined by prior correlation analysis among the predictor variables. The compiled model, named BxINROW/NET, is shown in Figure 2 and the probability values are shown for each node in the form of belief bars. In our moding scheme, we used GDD20 to represent PDs, i.e., "early" (193 to 317 GDD20), "intermediate" (317 to 327 GDD20), and "late" (327 to 334 GDD20). GDDH was used to represent lengths of growing periods, i.e., "minimum" (980 to 1300 GDDH), "intermediate" (1300 to 1495 GDDH), and "maximum" (1495 to 1710 GDDH). Yield grades were referred to as "low" or "high" for the low- and high-yielding intervals, respectively.

A simulation experiment was conducted to calculate posterior probabilities associated with yield outcomes (low and high) in response to different combinations of in-row spacing regimes, PDs (early and intermediate), and GDDH (Table 4). Greater probabilities for high US1 yield were generally associated with narrow $(66 \%$ to $78 \%$ of cases) and intermediate (56\% to $64 \%$ of cases) in-row spacing regimes given early and intermediate PDs. The percent net change in probabilities for attaining a high US1 yield associated with the use of a narrow in-row spacing instead of an intermediate in-row spacing ranged from $8 \%$ (early $\mathrm{PD}$, intermediate GDDH) to $23 \%$ (early PD, minimum GDDH) (Table 4). The addition of $\approx 50 \%$ more cuttings per hectare associated with the decision to adopt a narrow in-row spacing instead of an intermediate in-row spacing resulted in high US1 yields only $8 \%$ to $23 \%$ of the time given the PD and GDDH scenarios. Previous reports of 'Beauregard' in-row spacing trials have showed that US1 yield responses ranged from $-28 \%$ to $11 \%$ when planting density was increased by changing in-row spacing from $30 \mathrm{~cm}$ to 20 cm (Guertal and Kemble, 1997; Mulkey and McLemore, 1992; Mulkey et al., 1994).

The mean storage root count per hill under various in-row spacing regimens helped to explain these results (Table 5). It appeared that mean US1 count/hill decreased by $36 \%$ when in-row spacing was changed from intermediate $(30 \mathrm{~cm})$ to narrow $(20 \mathrm{~cm})$. This reduction in US1 count/hill likely offset any expectation of a $\approx 50 \%$ increase of US1 yield with a $\approx 50 \%$ increase in planting density. Previous reports that investigated in-row

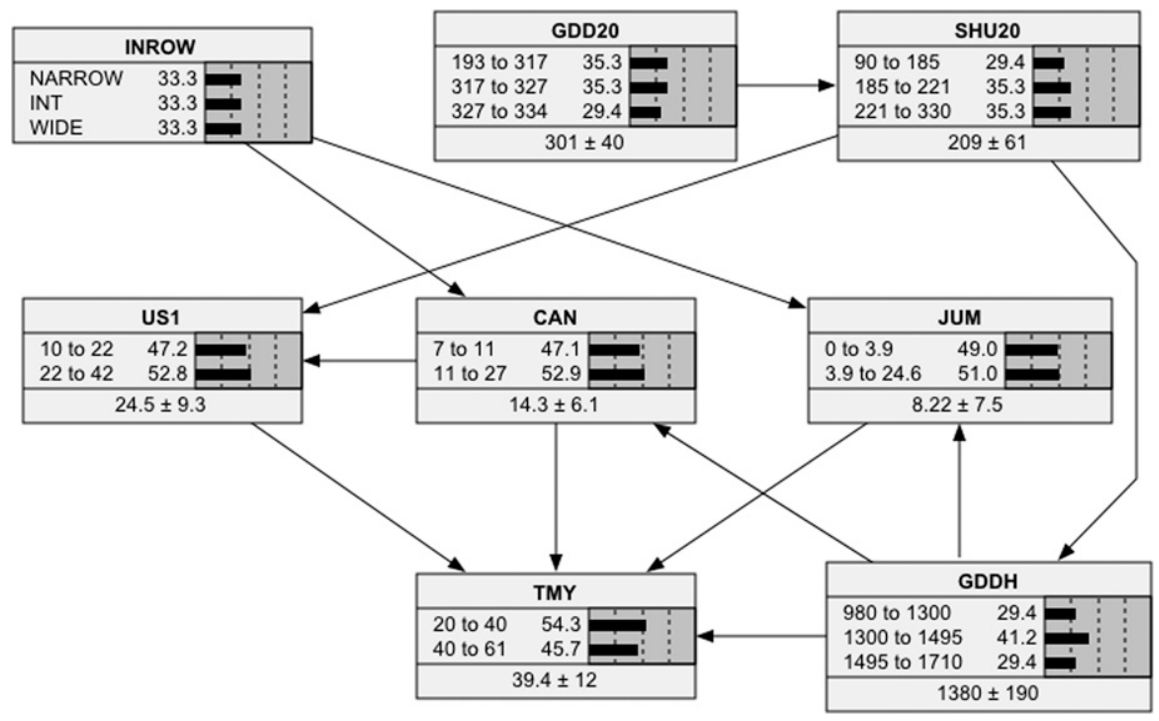

Fig. 2. A Bayesian belief network model, named BxINROW/NET, representing the causal effects of in-row spacing regimes, some agroclimatic variables, and growing degree-days on yield grades for 'Beauregard' sweetpotato grown in Louisiana. Horizontal bars (belief bars) and values within nodes are probabilities of states of each variable. Mean values \pm SD are shown below the belief bars. Natural log-transformed values were used to calculate the conditional probabilities. Corresponding nontransformed ranges are shown for all variable states or ranges. Input nodes: INROW $=$ in-row spacing where narrow $=20$ to $22 \mathrm{~cm}$, int (intermediate $)=30 \mathrm{~cm}$, and wide $=38$ to $40 \mathrm{~cm} ;$ SHU20 $=$ accumulated soil heat units $20 \mathrm{~d}$ after transplanting (DAT); GDD20 = accumulated air heat units 20 DAT; US1 = U.S. $\# 1$ yield grade; $C A N=$ canner yield grade; $J U M=$ jumbo yield grade; $T M Y=$ total marketable yield (US1 + CAN + JUM); GDDH = growing degree-days or accumulated heat units between 20 DAT and harvest. Yield $=\mathrm{t} \cdot \mathrm{ha}^{-1}$. Details of the experimental procedures are described in "Materials and Methods."

spacing effects in 'Beauregard' did not document root counts per hill. However, an earlier report by Zimmerley (1934) documented that Porto Rico cultivar showed $18 \%$ and $24 \%$ reductions in US1 count/hill when in-row spacing regimes were changed from $35 \mathrm{~cm}$ to 25 $\mathrm{cm}$ and $45 \mathrm{~cm}$ to $25 \mathrm{~cm}$, respectively.

Sulaiman and Sasaki (2001) reported that shoot and storage root dry weights per hill decreased with increased planting density (from $70 \mathrm{~cm}$ to $35 \mathrm{~cm}$ in-row spacing) in 'Shiroyutaka' and 'Norin No. 16' sweetpotatoes. The cultivar Shiroyutaka had shorter but more branches, whereas 'Norin No. 16' had relatively longer but fewer branches. Sulaiman and Sasaki (2001) documented that an increased planting density resulted in reductions ranging from $40 \%$ ('Shiroyutaka') to $60 \%$ ('Norin No. 16') and 20\% ('Shiroyutaka') to $50 \%$ ('Norin No. 16') in shoot and root dry weights per hill when sampled at 100 and 150 d, respectively. Kays (1985) has also previously documented that under various in-row spacing regimes $(15,30$, and $45 \mathrm{~cm})$, the number of branches in 'Jewel' sweetpotato decreased with increasing plant density. Sulaiman and Sasaki (2001) concluded that effects of planting densities were compensated by morphological plasticity (competition effects) in the cultivars that were studied. For example, the percent net change in probabilities for obtaining high US1 yields associated with the use of a wide inrow spacing instead of an intermediate inrow spacing ranged from $-21 \%$ (early $\mathrm{PD}$, maximum GDDH) to $0 \%$ (intermediate $\mathrm{PD}$, minimum GDDH) (Table 4). These results suggested that under certain conditions (intermediate PD and minimum GDDH), intermediate and wide in-row spacing regimes had similar US1 yield outcomes. Relative to intermediate in-row spacing, wide in-row spacing led to increased mean jumbo and total storage counts per hill, whereas US1 and 
Table 4. Posterior probabilities of yield outcomes as influenced by planting date, growing degree-days, and in-row spacing regimes for 'Beauregard' sweetpotato grown in Louisiana.

\begin{tabular}{|c|c|c|c|c|c|c|c|c|c|c|}
\hline \multirow[b]{3}{*}{$\mathrm{PD}^{\mathrm{z}}$} & \multirow[b]{3}{*}{$\mathrm{GDDH}^{\mathrm{y}}$} & \multirow[b]{3}{*}{ In-row ${ }^{x}$} & \multicolumn{8}{|c|}{ Probabilities of yield outcomes $(\%)^{\mathrm{w}}$} \\
\hline & & & \multicolumn{2}{|c|}{ U.S. \#1 } & \multicolumn{2}{|c|}{ Canner } & \multicolumn{2}{|c|}{ Jumbo } & \multicolumn{2}{|c|}{ TMY } \\
\hline & & & Low & High & Low & High & Low & High & Low & High \\
\hline \multirow[t]{15}{*}{ Early } & Minimum & Narrow & 31.4 & 68.6 & 20.0 & 80.0 & 100.0 & 0.0 & 52.0 & 48.0 \\
\hline & & & $(-29.1)$ & $(23.2)$ & $(-66.7)$ & $(100.0)$ & $(25.0)$ & $(-100.0)$ & $(-20.2)$ & $(37.9)$ \\
\hline & & Int & 44.3 & 55.7 & 60.0 & 40.0 & 80.0 & 20.0 & 65.2 & 34.8 \\
\hline & & & $(14.4)$ & $(-11.5)$ & $(33.3)$ & $(-50.0)$ & $(0.0)$ & $(0.0)$ & (15.8) & $(-29.6)$ \\
\hline & & Wide & 50.7 & 49.3 & 80.0 & 20.0 & 80.0 & 20.0 & 75.5 & 24.5 \\
\hline & Int & Narrow & 34.2 & 65.8 & 28.6 & 71.4 & 57.1 & 42.9 & 48.0 & 52.0 \\
\hline & & & $(-11.9)$ & $(7.5)$ & $(-33.3)$ & $(25.0)$ & $(-20.0)$ & $(50.0)$ & $(-13.8)$ & (17.4) \\
\hline & & Int & 38.8 & 61.2 & 42.9 & 57.1 & 71.4 & 28.6 & 55.7 & 44.3 \\
\hline & & & (23.7) & $(-15.0)$ & (66.4) & $(-49.9)$ & $(-80.0)$ & (199.7) & $(38.1)$ & $(-47.9)$ \\
\hline & & Wide & 48.0 & 52.0 & 71.4 & 28.6 & 14.3 & 85.7 & 76.9 & 23.1 \\
\hline & Maximum & Narrow & 25.0 & 75.0 & 0.0 & 100.0 & 20.0 & 80.0 & 12.5 & 87.5 \\
\hline & & & $(-34.0)$ & (20.8) & $(-100.0)$ & $(66.7)$ & $(0.0)$ & $(0.0)$ & $(-47.3)$ & $(14.7)$ \\
\hline & & Int & 37.9 & 62.1 & 40.0 & 60.0 & 20.0 & 80.0 & 23.7 & 76.3 \\
\hline & & & (33.8) & $(-20.6)$ & (100.0) & $(-66.7)$ & $(-100.0)$ & $(25.0)$ & (39.2) & $(-12.2)$ \\
\hline & & Wide & 50.7 & 49.3 & 80.0 & 20.0 & 0.0 & 100.0 & 33.0 & 67.0 \\
\hline \multirow[t]{15}{*}{ Int } & Minimum & Narrow & 28.9 & 71.1 & 20.0 & 80.0 & 100.0 & 0.0 & 50.2 & 49.8 \\
\hline & & & $(-31.5)$ & $(23.0)$ & $(-66.7)$ & $(100.0)$ & $(25.0)$ & $(-100.0)$ & $(-21.9)$ & $(39.5)$ \\
\hline & & Int & 42.2 & 57.8 & 60.0 & 40.0 & 80.0 & 20.0 & 64.3 & 35.7 \\
\hline & & & $(0.0)$ & $(0.0)$ & $(0.0)$ & $(0.0)$ & $(0.0)$ & $(0.0)$ & $(0.0)$ & $(0.0)$ \\
\hline & & Wide & 42.2 & 57.8 & 60.0 & 40.0 & 80.0 & 20.0 & 64.3 & 35.7 \\
\hline & Int & Narrow & 31.7 & 68.3 & 28.6 & 71.4 & 57.1 & 42.9 & 46.9 & 53.1 \\
\hline & & & $(-13.2)$ & $(7.6)$ & $(-33.3)$ & $(25.0)$ & $(-20.0)$ & $(50.0)$ & $(-14.4)$ & (17.5) \\
\hline & & Int & 36.5 & 63.5 & 42.9 & 57.1 & 71.4 & 28.6 & 54.8 & 45.2 \\
\hline & & & $(26.0)$ & $(-15.0)$ & (66.4) & $(-49.9)$ & $(-80.0)$ & (199.7) & (38.9) & $(-47.1)$ \\
\hline & & Wide & 46.0 & 54.0 & 71.4 & 28.6 & 14.3 & 85.7 & 76.1 & 23.9 \\
\hline & Maximum & Narrow & 22.2 & 77.8 & 0.0 & 100.0 & 20.0 & 80.0 & 11.1 & 88.9 \\
\hline & & & $(-37.6)$ & (20.8) & $(-100.0)$ & $(66.7)$ & $(0.0)$ & $(0.0)$ & $(-50.7)$ & $(14.7)$ \\
\hline & & Int & 35.6 & 64.4 & 40.0 & 60.0 & 20.0 & 80.0 & 22.5 & 77.5 \\
\hline & & & (37.4) & $(-20.7)$ & (100.0) & $(-66.7)$ & $(-100.0)$ & $(25.0)$ & (41.8) & $(-12.1)$ \\
\hline & & Wide & 48.9 & 51.1 & 80.0 & 20.0 & 0.0 & 100.0 & 31.9 & 68.1 \\
\hline
\end{tabular}

${ }^{\text {zPD }}=$ planting date. GDD20 (accumulated heat units 20 DAT) was used to represent PDs: early = 193 to 317 GDD20; Int (intermediate) = 317 to 327 GDD20. The states for soil heat units 20 DAT (SHU20) were set at the same level as GDD20 for all simulation experiments.

${ }^{\mathrm{y}} \mathrm{GDDH}=$ growing degree-days to harvest. GDDH: minimum $=80$ to $1300 \mathrm{GDDs}$; Int $=1300$ to 1495 GDDs; maximum $=1495$ to 1710 GDDs .

${ }^{\mathrm{x}}$ In-row $=$ in-row spacing regimes. Narrow $=20$ to $22 \mathrm{~cm}$; Int $=30 \mathrm{~cm}$; and wide $=38$ to $40 \mathrm{~cm}$.

"Values in parentheses below and above each probability (\%) estimates of yield for narrow and wide in-row spacing regimes, respectively, represent percentage net change of probability relative to intermediate spacing. Details of the experimental methods and other procedures are defined in "Materials and Methods."

Table 5. Mean count per hill for U.S. \#1, canners, jumbos, and total storage roots under various in-row spacing regimes for 'Beauregard' sweetpotato grown in Louisiana.

\begin{tabular}{lcccc}
\hline & \multicolumn{4}{c}{ Count $^{2}$} \\
\cline { 2 - 5 } In-row $(\mathrm{cm})$ & U.S. \#1 & Canners & Jumbos & Total \\
\hline 20 & $1.6(0.3) \mathrm{b}$ & $3.3(0.7) \mathrm{a}$ & $0.3(0.1) \mathrm{ab}$ & $5.2(0.7) \mathrm{b}$ \\
30 & $2.2(0.2) \mathrm{a}$ & $3.2(0.4) \mathrm{a}$ & $0.1(0.0) \mathrm{b}$ & $5.5(0.5) \mathrm{b}$ \\
40 & $2.7(0.4) \mathrm{a}$ & $4.2(0.6) \mathrm{a}$ & $0.6(0.2) \mathrm{a}$ & $7.5(0.4) \mathrm{a}$
\end{tabular}

${ }^{\mathrm{z}}$ U.S. \#1 (5.1 to $8.9 \mathrm{~cm}$ in diameter and 7.6 to $22.9 \mathrm{~cm}$ long), canner (2.5 to $5.1 \mathrm{~cm}$ in diameter and 5.1 to $17.8 \mathrm{~cm}$ in length), and jumbo (larger than both groups but marketable). Total = U.S. \#1 + canners + jumbos. Mean separation within columns by least significant difference at $P<0.05$. Values in parentheses $=$ SE. Storage root count data were obtained from two replications in each of three planting dates in 2010 (12 May, 20 May, and 27 May). The storage root count data were pooled and analysis of variance was performed on natural log-transformed values. The non-transformed values are shown. Details of the experimental methods and other procedures are defined in "Materials and Methods."

canner counts did not vary (Table 5). This indicated that in-row spacing regimens wider than 38 to $40 \mathrm{~cm}$ likely did not lead to further increases in 'Beauregard' US1 count/ hill.

The storage root count data were consistent with the BBN model simulation results. Wide in-row spacing and maximum GDDH generally showed a higher probability $(100 \%$ of cases) for obtaining a high yield of JUM or oversized roots ( 5 to $27 \mathrm{t} \cdot \mathrm{ha}^{-1}$ ) across all ranges of GDD20 and SHU20 (Table 4). The implicit recognition that growing period mitigated in-row spacing effects was consistent with a past observation that presumptive in-row spacing effects depended on harvest dates (Schultheis et al., 1999).

When considered along with current available evidence about storage root initiation and its direct influence on yield determination, it appeared that optimum air and soil temperatures 20 DAT increased the probability for attaining a high US1 yield if harvested within the optimum time (minimum to intermediate GDDH). When dug at a later date (maximum GDDH), the probability for obtaining oversized roots (jumbo) increased with the concomitant decrease of probability for a high US1 yield in plots with a wide in-row spacing (lower planting density) (Table 4). This indicated that storage roots achieved US1 size sooner as a result of less competition for resources under conditions of a lower planting density; the delayed harvest moved these roots to the next size category (jumbo or oversized). This is similar to experimental results from other root and tuber crops such as carrots (Daucus carota) (da Silva et al., 2008), potatoes (Solanum tuberosum) (Love and Thompson-Johns, 1999), and table beet (Beta vulgaris) (Kikkert et al., 2010) in which delayed harvest in plots with lower planting densities led to the increase of large or oversized storage roots and tubers.

A second simulation demonstrated the potential use of BxINROW/NET as a foundation model for developing BDNs for fresh market and processing scenarios of sweetpotato 
production. The latter scenario is a response to recent industry developments that have created an option for producers to grow entirely for the processing market, e.g., French fries and other specialty products. The fresh market and processing BDNs are shown in Figure 3. After converting the BBN foundation model into a BDN, the INROW node now showed the calculated net return opposite each in-row spacing regime. The fresh market and processing BDNs were used to calculate net return per hectare as influenced by certain combinations of in-row spacing regimes, PDs, and growing periods (Table 6).

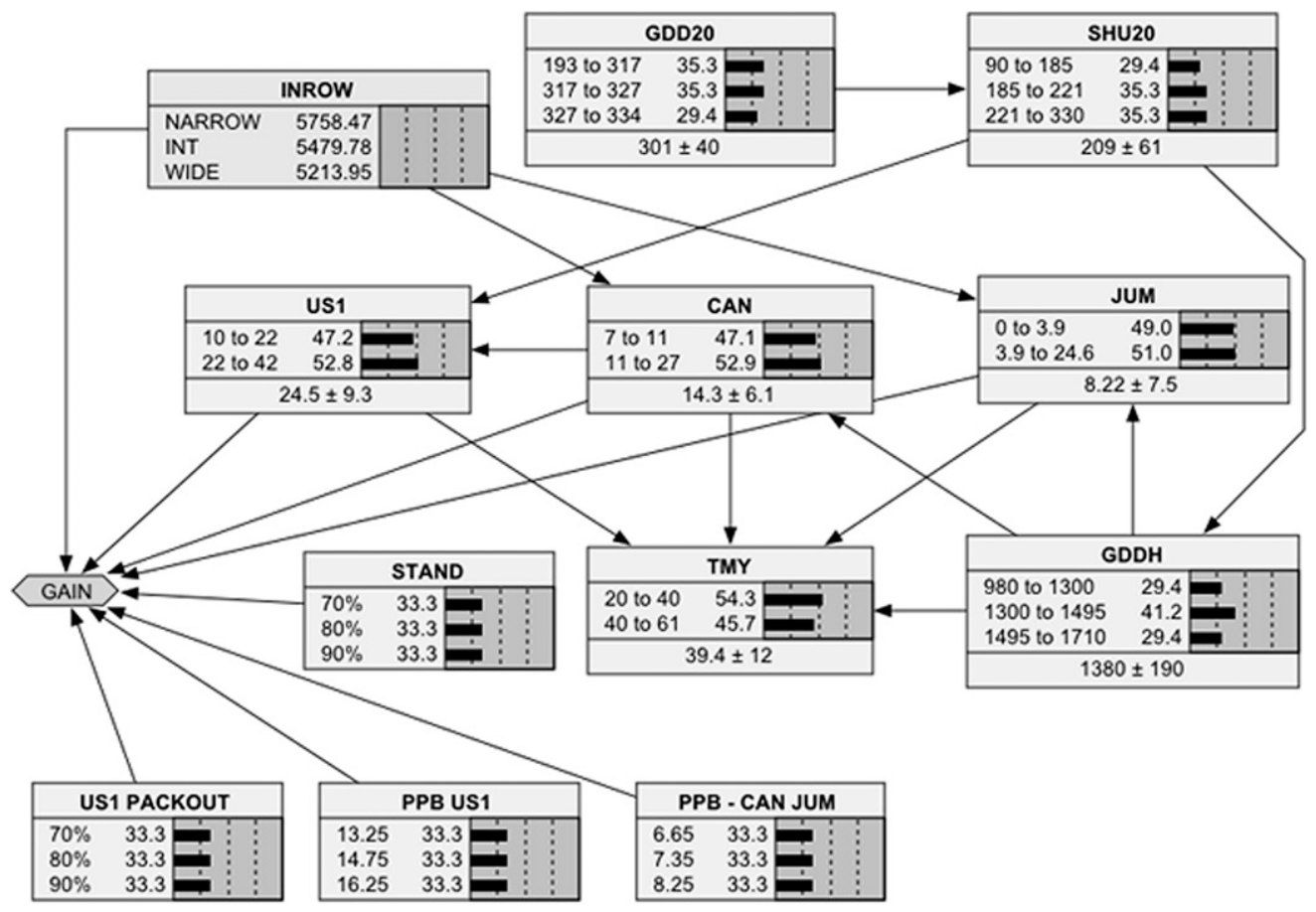

Fresh Market Decision Network

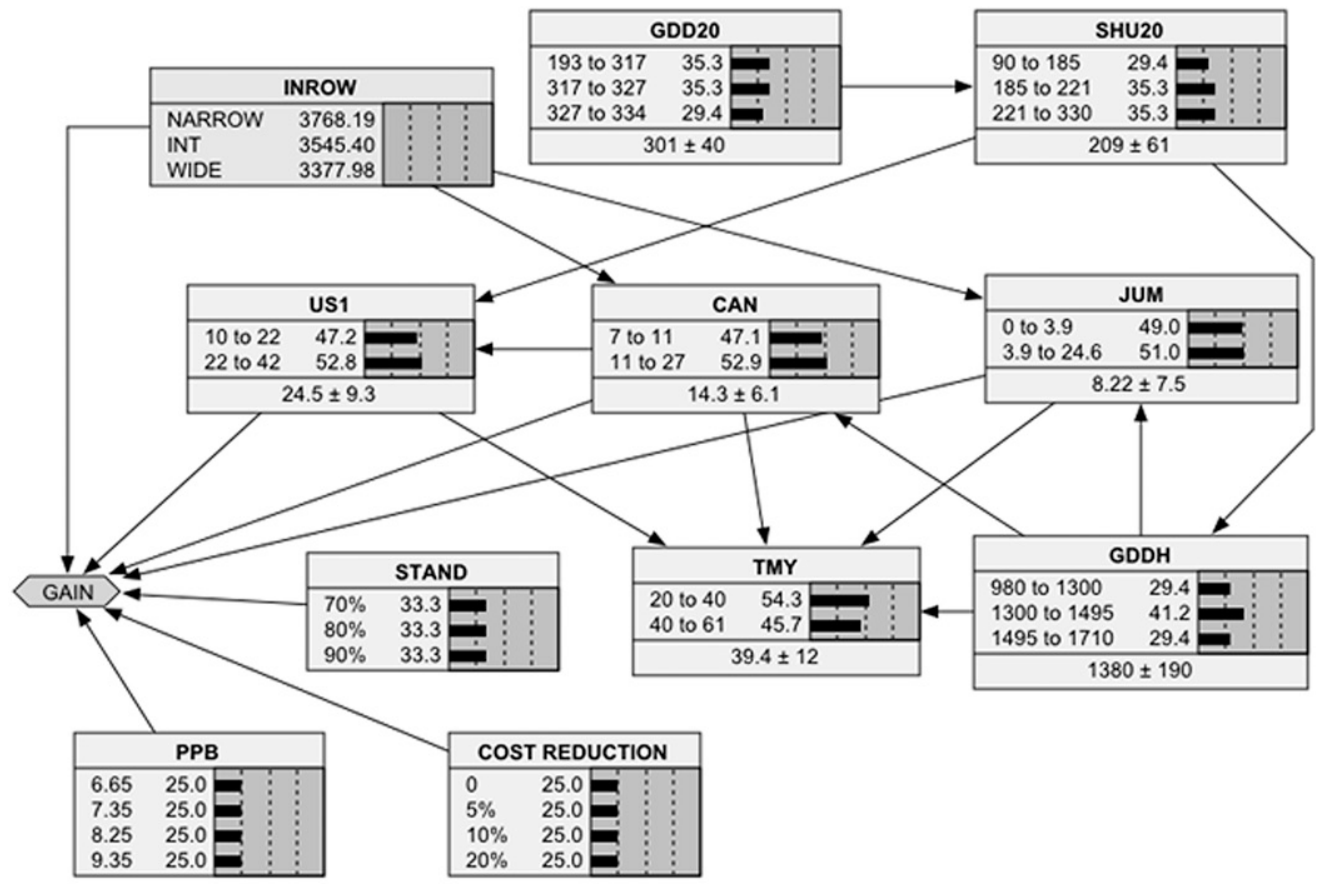

Processing Decision Network

Fig. 3. Bayesian decision networks representing gain in value (net return per hectare) associated with in-row spacing regimes for fresh market and processing sweetpotato production as influenced by some agroclimatic variables, growing degree-days, price per box, packout rates, and stand deficiency for 'Beauregard' sweetpotato grown in Louisiana. INROW decision node shows the calculated net return opposite each in-row spacing regime. Nodes with mean values \pm SD shown below the belief bars (horizontal bars) are quantitative nodes. Horizontal bars and values within nodes are probabilities of states of each discretized quantitative variable. All other nodes are discrete nodes. INROW $=$ in-row spacing where narrow $=20$ to $22 \mathrm{~cm}$, int (intermediate) $=30 \mathrm{~cm}$, and wide $=38$ to $40 \mathrm{~cm}$; SHU20 = accumulated soil heat units $20 \mathrm{~d}$ after transplanting (DAT); GDD20 = accumulated air heat units 20 DAT; US1 = U.S. \#1 yield grade; $\mathrm{CAN}=$ canner yield grade; $\mathrm{JUM}=$ jumbo yield grade; TMY $=$ total marketable yield $(\mathrm{US} 1+\mathrm{CAN}+\mathrm{JUM})$; GDDH $=$ growing degree-days or accumulated heat units between 20 DAT and harvest; $\mathrm{PPB}=$ price per box; PACKOUT $=$ packout rate; STAND = percent surviving stand; COST REDUCTION $=$ percent reduction of production cost per hectare. Yield $=\mathrm{t} \cdot \mathrm{ha}^{-1}$. Details of the experimental procedures are described in "Materials and Methods." 
Table 6. Simulation of net returns for representative scenarios of fresh market and processing production as influenced by stand, cost reduction scenarios for processing production, planting date, growing degree-days, and in-row spacing regimes for 'Beauregard' sweetpotato grown in Louisiana.

\begin{tabular}{|c|c|c|c|c|c|c|c|c|c|c|c|c|c|c|c|}
\hline \multirow{5}{*}{$\mathrm{PD}^{\mathrm{z}}$} & \multirow[b]{5}{*}{$\mathrm{GDDH}^{\mathrm{y}}$} & \multirow[b]{5}{*}{ In-row $^{x}$} & \multicolumn{13}{|c|}{ Stand $^{\mathrm{w}}$} \\
\hline & & & \multirow{4}{*}{$\frac{\text { Fresh }}{80 \%}$} & \multicolumn{12}{|c|}{ Processing } \\
\hline & & & & \multicolumn{6}{|c|}{$80 \%$} & \multicolumn{6}{|c|}{$90 \%$} \\
\hline & & & & \multicolumn{12}{|c|}{ Cost reduction (\%) } \\
\hline & & & & 0.0 & & 10.0 & & 20.0 & & 0.0 & & 10.0 & & 20.0 & \\
\hline \multirow[t]{5}{*}{ Early } & Minimum & Narrow & $\begin{array}{r}6035.0 \\
(11.3)\end{array}$ & $\begin{array}{r}3527.0 \\
(13.2)\end{array}$ & $(-41.6)$ & $\begin{array}{r}4204.0 \\
(12.1)\end{array}$ & $(-30.3)$ & $\begin{array}{r}4881.0 \\
(11.4)\end{array}$ & $(-19.1)$ & $\begin{array}{r}4814.0 \\
(12.0)\end{array}$ & $(-20.2)$ & $\begin{array}{r}5491.0 \\
(11.4)\end{array}$ & $(-9.0)$ & $\begin{array}{r}6168.0 \\
(10.8)\end{array}$ & $(2.2)$ \\
\hline & & Int & $\begin{array}{r}5423.0 \\
(-8.4)\end{array}$ & $\begin{array}{l}3115.0 \\
(-11.4)\end{array}$ & $(-42.6)$ & $\begin{array}{r}3749.0 \\
(-9.9)\end{array}$ & $(-30.9)$ & $\begin{array}{r}4383.0 \\
(-8.9)\end{array}$ & $(-19.2)$ & $\begin{array}{r}4297.0 \\
(-9.8)\end{array}$ & $(-20.8)$ & $\begin{array}{r}4931.0 \\
(-8.9)\end{array}$ & $(-9.1)$ & $\begin{array}{r}5565.0 \\
(-8.2)\end{array}$ & (2.6) \\
\hline & Maximum & Narrow & $\begin{array}{r}6493.0 \\
(8.3)\end{array}$ & $\begin{array}{r}4164.0 \\
(10.2)\end{array}$ & $(-35.9)$ & $\begin{array}{r}4841.0 \\
(9.7)\end{array}$ & $(-25.4)$ & $\begin{array}{r}5518.0 \\
(9.4)\end{array}$ & $(-15.0)$ & $\begin{array}{r}5530.0 \\
(9.7)\end{array}$ & $(-14.8)$ & $\begin{array}{r}6207.0 \\
(9.4)\end{array}$ & $(-4.4)$ & $\begin{array}{r}6885.0 \\
(9.1)\end{array}$ & (6.0) \\
\hline & & Int & $\begin{array}{r}5997.0 \\
-9.1\end{array}$ & $\begin{array}{l}3777.0 \\
(-11.5)\end{array}$ & -37.0 & $\begin{array}{l}4411.0 \\
(-10.3)\end{array}$ & -26.4 & $\begin{array}{r}5045.0 \\
(-9.3)\end{array}$ & -15.9 & $\begin{array}{l}5042.0 \\
(-10.2)\end{array}$ & -15.9 & $\begin{array}{r}5676.0 \\
(-9.3)\end{array}$ & -5.4 & $\begin{array}{r}6310.0 \\
(-8.7)\end{array}$ & 5.2 \\
\hline & & Wide & 5450.0 & 3341.0 & $(-38.7)$ & 3958.0 & $(-27.4)$ & 4575.0 & $(-16.1)$ & 4530.0 & $(-16.9)$ & 5147.0 & $(-5.6)$ & 5764.0 & $(5.8)$ \\
\hline \multirow{3}{*}{ Late } & Maximum & Narrow & $\begin{array}{r}5493.0 \\
(3.0)\end{array}$ & $\begin{array}{r}3439.0 \\
(4.3)\end{array}$ & $(-37.4)$ & $\begin{array}{r}4116.0 \\
(4.7)\end{array}$ & $(-25.1)$ & $\begin{array}{r}4793.0 \\
(5.0)\end{array}$ & $(-12.7)$ & $\begin{array}{r}4716.0 \\
(4.7)\end{array}$ & $(-14.1)$ & $\begin{array}{r}5393.0 \\
(5.0)\end{array}$ & $(-1.8)$ & $\begin{array}{r}6070.0 \\
\quad(5.2)\end{array}$ & $(10.5)$ \\
\hline & & Int & $\begin{array}{c}5335.0 \\
(-3.9)\end{array}$ & $\begin{array}{r}3298.0 \\
(-5.8)\end{array}$ & $(-38.2)$ & $\begin{array}{c}3932.0 \\
(-5.3)\end{array}$ & $(-26.3)$ & $\begin{array}{r}4566.0 \\
(-4.9)\end{array}$ & $(-14.4)$ & $\begin{array}{r}4503.0 \\
(-5.2)\end{array}$ & $(-15.6)$ & $\begin{array}{r}5137.0 \\
(-4.9)\end{array}$ & $(-3.7)$ & $\begin{array}{c}5771.0 \\
(-4.7)\end{array}$ & $(8.2)$ \\
\hline & & Wide & 5128.0 & 3108.0 & $(-39.4)$ & 3725.0 & $(-27.4)$ & 4341.0 & $(-15.3)$ & 4267.0 & $(-16.8)$ & 4884.0 & $(-4.8)$ & 5501.0 & (7.3) \\
\hline
\end{tabular}

${ }^{2} \mathrm{PD}=$ planting date. GDD20 (accumulated heat units 20 DAT) was used to represent PDs: early $=193$ to 317 GDD20; late $=327$ to 334 GDD20.

${ }^{\mathrm{y}} \mathrm{GDDH}=$ growing degree-days to harvest. Minimum $=980$ to $1300 \mathrm{GDDs}$; Int (intermediate) $=1300$ to 1495 GDDs; and maximum $=1495$ to $1710 \mathrm{GDDs}$.

${ }^{x}$ In-row $=$ in-row spacing. Narrow $=20$ to $22 \mathrm{~cm}$; Int $=30 \mathrm{~cm}$; wide $=38$ to $40 \mathrm{~cm}$.

${ }^{\text {w}}$ Values in parentheses below and above each estimate of net return per hectare for narrow and wide in-row spacing regimes, respectively, represent percent net gain in utility relative to intermediate spacing. Values in parentheses to the right of each estimate of net return per hectare for processing in-row spacing regimes represent percent net gain in utility relative to similar spacing in fresh market production. Stand = percent stand survival; Fresh $=$ fresh market production; Processing = production intended for processing; Cost reduction $=$ percent reduction in cost of production. Details of the experimental methods and other procedures are defined in "Materials and Methods."

Additional scenarios for the processing BDN included STAND ( $80 \%$ and $90 \%)$ and COST REDUCTION (0\%, 10\%, and 20\%). There was only one STAND (80\%) scenario for the fresh market simulations. In all scenarios, the following were held constant: US1 PACKOUT $=80 \%$ (fresh market only), US1 PPB $=\$ 14.75$ (fresh market only), and PPB for processing $=\$ 8.25$. For fresh market simulations, it was assumed that the price for canners and jumbos sold to canners or processors was similar to the prevailing processing price.

Given these scenarios, highest estimated net returns for fresh market (\$6035 to \$6493) were associated with early PDs and narrow in-row spacing. In fresh market BDN simulations, adopting a narrow in-row spacing instead of an intermediate in-row spacing regime resulted in percent gains in net return ranging from $2 \%$ (late $\mathrm{PD}$ and intermediate GDDH) to $11 \%$ (early PD and minimum GDDH). In contrast, the decision to decrease planting density by changing in-row spacing from intermediate to wide was associated with percent gains in net return ranging from $-9 \%$ (early PD and maximum GDDH) to $0 \%$ (late PD and medium GDDH).

A decision-maker can use the BDN fresh market model to identify the decision solution with the greatest net return. For example, if the management objective is to reduce risk from late-season insect injury or late-season rainfall associated with an extended growing season (or maximum GDDH), then the appropriate combination of in-row spacing and minimum or intermediate GDDH that brings about maximum net return needs to be identified. Another consideration might be to set $20 \%$ increase in net return as the threshold for deciding among in-row spacing options, i.e., given a choice of two in-row spacing regimes, the spacing regimen with the least planting density will be adopted if the predicted net return associated with an increased planting density does not exceed $20 \%$. Given the previous risk reduction and net return scenarios, the following are solutions for obtaining maximum expected utility associated with in-row spacing decisions given the various $\mathrm{PD}$ and GDDH combinations for fresh market production of 'Beauregard' sweetpotato in Louisiana: intermediate in-row spacing (early and intermediate PDs, intermediate GDDH) and wide in-row spacing (late PDs and intermediate GDDH).

Processing BDN scenarios showed that STAND and COST REDUCTION were important variables in helping to ensure that net returns associated with $100 \%$ processingoriented production were comparable to fresh market production (Table 6). Given a processing scenario where STAND $=80 \%$ and COST REDUCTION $=20 \%$, the predicted percent gains in net return ranged from $-20 \%$ to $-13 \%$ relative to fresh market production. If STAND was $90 \%$, a $20 \%$ COST REDUCTION showed that expected net returns associated with processing matched or slightly exceeded fresh market production, in which predicted percent gains in net return ranged from $2 \%$ to $11 \%$. All of these processing simulation scenarios showed that the probability for a high US1 yield was consistently greater than $50 \%$ of cases. If US1 yield was low, the predicted net returns per hectare were significantly reduced, ranging from $\$ 2918$ to $\$ 3749$ for intermediate in-row spacing (data not shown). This simulation scenario suggested that in addition to reducing production costs and improving plant stand, US1 yield needed to be maximized to achieve the desired results in a processingoriented production.

\section{Conclusion}

Our results were consistent with the observation that BDNs demonstrated the impacts of decisions on a producer's system and permitted evaluation of these impacts according to the producer's own priorities and criteria for financial gain (Robertson and Wang, 2004). The BBN and BDNs served as interactive visual decision support tools for determining optimal in-row spacing by identifying the variables that increased probabilities for optimal yields and reducing the risk for negative financial return for 'Beauregard' 
sweetpotato grown in Louisiana. These results were consistent with the capability of BBNs to quantify risk under conditions of uncertainty or incomplete data (McCann et al., 2006; Uusitalo, 2007).

We have also used the BBN to help explain previous conflicting observations about the effects of in-row spacing in 'Beauregard' sweetpotato yields. This was achieved in part by taking into account the growing period and the effects of some agroclimatic variables that have been shown to influence storage root initiation 20 DAT. After accounting for these variables, there was increased predictability of yield outcomes for fresh market or processing scenarios. The results of the simulation experiments suggested that environmental conditions during storage root initiation phase interacted with in-row spacing and growing period to help determine yield outcome in 'Beauregard' sweetpotato grown in irrigated conditions in Louisiana. Our results provided additional evidence to a previous observation that as in-row spacing increased, the total yield decreased slightly, whereas the number of oversize roots increased and that additional yields associated with higher planting densities did not consistently compensate for higher production costs associated with additional transplants (Kays, 1985).

Finally, Tables 4 and 6 demonstrated that decision support tools need not be computerbased and such tools can be made available in a printed format that contain "lookup tables" that can assist producers and crop consultants in decision-making (Cox, 1996). As a result of its empirical nature, the current model is only applicable to the cultivar, irrigated growing conditions, location, and range of agroclimatic variables that were sampled. However, its applicability in other cultivars or locations can be determined through relatively simple validation and calibration tests. The current model's predictive accuracy can also be improved by incorporating new experimental data and expert knowledge.

One potential gap in current knowledge about the relationship among agroclimatic and management variables and in-row spacing effects is the potential mitigating influence of an increased supplemental irrigation amount or frequency with higher planting densities. This represents an important limitation of the current work where experimental plots were subjected to a uniform irrigation regime. Based on work in other crops, it appears that further yield responses are possible if irrigation amounts or frequencies are optimized with different planting densities (Debaeke and Aboudrare, 2004; Eastham et al., 1990). The relationship between planting density and irrigation regime in sweetpotato represents an area that needs to be investigated in future research activities.

The models and the modeling data set are available on request from the authors. A fully functional demonstration version of Netica can be downloaded to view and run these models. These models are unencrypted to allow modification and revision of the conditional probability and utility tables if empirical data, expert inputs, and cost structure data that are specific to a location or production environment become available.

\section{Literature Cited}

Bouwkamp, J. 1985. Production requirements, p. 1-33. In: Bouwkamp, J. (ed.). Sweetpotato products: A natural resource for the tropics. CRC Press, Inc., Boca Raton, FL.

Cain, J. 2001. Planning improvements in natural resources management: Guidelines for using Bayesian networks to support the planning and management of development programmes in the water sector and beyond. Centre for Ecology \& Hydrology, Wallingford, UK.

Clark, C.A. and M.W. Hoy. 2006. Effects of common viruses on yield and quality of Beauregard sweetpotato in Louisiana. Plant Dis. 90:83-88.

Constantin, R.J., T.P. Hernandez, and L.G. Jones. 1974. Effects of irrigation and nitrogen fertilization on quality of sweet potatoes. J. Amer. Soc. Hort. Sci. 99:308-310.

Cox, P.G. 1996. Some issues in the design of agricultural decision support systems. Agr. Syst. $52: 355-381$.

da Silva, J.B.C., J.V. Vieira, and M.M. Lana. 2008. Processing yield of the carrot cultivar Esplanada as affected by harvest time and planting density. Sci. Hort. 115:218-222.

Debaeke, P. and A. Aboudrare. 2004. Adaptation of crop management to water-limited environments. Eur. J. Agron. 21:433-446.

Eastham, J., C.W. Rose, D.A. Charles-Edwards, D.M. Cameron, and S.J. Rance. 1990. Planting density effects on water use efficiency of trees and pasture in an agroforestry experiment. N. Z. J. For. Sci. 20:39-53.

Edmond, J.B. and G.R. Ammerman. 1971. Sweet potatoes: Production, processing, marketing. AVI Publishing, Westport, CT.

Fawcett, T. 2006. An introduction to ROC analysis. Pattern Recognit. Lett. 27:861-874.

Gu, Y., D.R. Peiris, J.W. Crawford, J.W. McNichol, B. Marshall, and R.A. Jefferies. 1994. An application of belief networks to future crop production, p. 305-309. Proc. 10th Conf. on Artificial Intelligence for Applications. San Antonio, TX.

Guertal, E.A. and J.A. Kemble. 1997. Nitrogen rate and within-row plant spacing effects on sweetpotato yield and grade. J. Plant Nutr. 20:355360.

Hinson, R.A. and J.E. Boudreaux. 2009. Louisiana vegetable crops 2009 projected commodity costs and returns. A.E.A. Series No. 263. Mar. 2009.

Jensen, E.V. 2001. Bayesian networks and decision graphs. Springer-Verlag, New York, NY.

Kays, S.J. 1985. The physiology of yield in the sweetpotato, p. 79-132. In: Bouwkamp, J. (ed.). Sweetpotato products: A natural resource for the tropics. CRC Press, Boca Raton, FL.

Kikkert, J.R., S. Reiners, and B.K. Gugino. 2010. Row width, population density, and harvest date effects on marketable yield of table beet. HortTechnology 20:560-567.

Kristensen, K. and I.A. Rasmussen. 2002. The use of a Bayesian network in the design of a decision support system for growing malting barley without use of pesticides. Comp. Elec. Agr. 33:197-217.

Kuhnert, P.M. and K.R. Hayes. 2009. How believable is your BBN? p. 4319-4325. In: Anderssen, R.S., R.D. Braddock, and L.T.H. Newham (eds.). 18th World IMACS Congress and MODSIM09 Int. Congress on
Modelling and Simulation. Modelling and Simulation Society of Australia and New Zealand and International Association for Mathematics and Computers in Simulation, July 2009, Cairns, Australia.

Love, S.L. and A. Thompson-Johns. 1999. Seed piece spacing influences yield, tuber size distribution, stem and tuber density, and net returns of three processing potato cultivars. HortScience 34:629-633.

Lundstrom, D.R. and E.C. Stegman. 1988. Irrigation scheduling by the checkbook method. NDSU Extension Service AE-792.

Marcot, B.G., J.D. Steventon, G.D. Sutherland, and R.K. McCann. 2006. Guidelines for developing and updating Bayesian belief networks applied to ecological modeling and conservation. Can. J. For. Res. 36:3063-3074.

McCann, R.K., B.G. Marcot, and R. Ellis. 2006. Bayesian belief networks: Applications in ecology and natural resource management. Can. J. For. Res. 36:3053-3062.

Mulkey, W.A. and J.H. Hernandez. 1994. Compendium Sweetpotato Foundation programs: Louisiana's sweetpotato foundation seed program. HortTechnology 4:228-230.

Mulkey, W.A. and W.B. McLemore III. 1992. Inrow plant spacing by planting date studies. Sweet Potato Research. LAES Mimeo Series No. 69.

Mulkey, W.A., W.B. McLemore, and T.P. Talbot. 1994. In-row plant spacing by transplanting date studies. Sweet Potato Research. LAES Mimeo Series No. 89.

Myllymaki, P., T. Silander, H. Tirri, and P. Uronen. 2002. B-Course: A web-based tool for Bayesian and causal analysis. Intl. J. Artif. Intell. Tools 11:369-387.

Nash, D. and M. Hannah. 2011. Using Monte-Carlo simulations and Bayesian networks to quantify and demonstrate the impact of fertilizer best management practices. Environ. Model. Softw. 26:1079-1088.

Newton, A.C., G.B. Stewart, A. Diaz, D. Golicher, and A.S. Pullin. 2007. Bayesian belief networks as a tool for evidence-based conservation management. J. Nat. Conserv. 15:144-160.

Pale, S., S.C. Mason, and T.D. Galusha. 2003. Planting time for early-season pearl millet and grain sorghum in Nebraska. Agron. J. 95:10471053.

Park, S.J., C.S. Hwang, and P.L.G. Vlek. 2005. Comparison of adaptive techniques to predict crop yield response under varying soil and land management conditions. Agr. Syst. 85:59-81.

Ravi, V. and P. Indira. 1999. Crop physiology of sweet potato, p. 227-316. In: Janick, J. (ed.). Horticultural reviews. Vol. 23. John Wiley \& Sons, Inc., New York, NY.

Reiz, B. and L. Csato. 2009. Bayesian network classifier for medical data analysis. Intl. J. Computers Communications \& Control. 4:65-72.

Riha, S.J., D.S. Wilks, and P. Simoens. 1996. Impact of temperature and precipitation variability on crop model predictions. Clim. Change 32:293311.

Robertson, D. and Q.J. Wang. 2004. Bayesian networks for decision analyses-an application to irrigation system selection. Aust. J. Exp. Agr. 44:145-150.

Schultheis, J.R., S.A. Walters, and D.E. Adams. 1999. In-row plant spacing and date of harvest of 'Beauregard' sweetpotato affect yield and return on investment. HortScience 34:12291233.

Steinbauer, C.E. and L.J. Kushman. 1971. Sweetpotato culture and diseases. U.S.D.A. Agri. Handbook 388. 
Sulaiman, H. and O. Sasaki. 2001. Studies on effect of planting density on the growth and yield of sweet potato (Ipomoea batatas Lam.). Mem. Fac. Agr. Kagoshima Univ. 37:1-10.

Tari, F. 1996. A Bayesian network for predicting yield response of winter wheat to fungicide programmes. Comp. Elec. Agr. 15:111121.

Togari, Y. 1950. A study of tuberous root formation in sweet potato. Bull. Nat. Agr. Expt. Sta. Tokyo 68:1-96.

U.S. Department of Agriculture. 2005. United States standards for grades of sweetpotatoes. 22 Feb. 2011. <http://www.ams.usda.gov/AMSv1.0/ getfile $? \mathrm{dDocName}=$ STELPRDC5050330 $>$.
Uusitalo, L. 2007. Advantages and challenges of Bayesian networks in environmental modeling. Ecol. Modell. 203:312-318.

Villordon, A., C. Clark, D. Ferrin, and D. LaBonte. 2009a. Using growing degree days, climatic variables, linear regression, and data mining methods to help improve prediction of sweetpotato harvest date and yield in Louisiana. HortTechnology 19:133-134.

Villordon, A., D.R. LaBonte, N. Firon, Y. Kfir, E. Pressman, and A. Schwartz. 2009b. Characterization of adventitious root development in sweetpotato. HortScience 44:651-655.

Villordon, A., D. LaBonte, and J. Solis. 2011. Using a scanner-based minirhizotron system to characterize sweetpotato adventitious root development during the initial storage root bulking stage. HortScience 46:513-517.

Villordon, A., J. Solis, D. LaBonte, and C. Clark. 2010. Development of a prototype Bayesian belief network representing the relationship between fresh market yield and some agroclimatic variables known to influence storage root initiation in sweetpotato. HortScience 45:1167-1177.

Watt, E.W. and A.T. Bui. 2008. Evaluation of dynamic Bayesian belief network to predict osteoarthritic knee pain using data from the osteoarthritis initiative. AMIA Annu. Symp. Proc. p. 788-792.

Zimmerley, H.H. 1934. The effect of plant spacing on the development of sweet potato storage roots. Proc. Amer. Soc. Hort. 32:494-497. 